Research Article

\title{
Synthesis of Bio-Inspired Silver Nanoparticles by Ripe and Unripe Fruit Extract of Tinospora cordifolia and Its Antioxidant, Antibacterial and Catalytic Studies
}

\author{
Praveena Kanagala ${ }^{1 \dagger}$, Susmila Aparna Gaddam ${ }^{2 \dagger}$, Priyanka Gunji ${ }^{1}$, Venkata Subbaiah Kotakadi ${ }^{1 \mp}$, \\ Chandra Mouli Kalla ${ }^{3}$, Vijaya Tartte ${ }^{3}$, Divi Venkata Ramana Sai Gopal ${ }^{1}$ \\ ${ }^{1}$ DST-PURSE Centre, Sri Venkateswara University, Tirupati, Andhra Pradesh, India. \\ ${ }^{2}$ Department of Virology, Sri Venkateswara University, Tirupati, Andhra Pradesh, India. \\ ${ }^{3}$ Department of Botany, Sri Venkateswara University, Tirupati, Andhra Pradesh, India. \\ Corresponding authors. E-mail: kotakadi72@gmail.com; susmilaaparna@gmail.com \\ $\dagger$ Authors contributed equally to the work.
}

Received: Nov. 13, 2019; Accepted: Jul. 21, 2020; Published: Aug. II, 2020

Citation: Praveena Kanagala, Susmila Aparna Gaddam, Priyanka Gunji, Venkata Subbaiah Kotakadi, Chandra Mouli Kalla, Vijaya Tartte, and Divi Venkata Ramana Sai Gopal, Synthesis of Bio-Inspired Silver Nanoparticles by Ripe and Unripe Fruit Extract of Tinospora cordifolia and Its Antioxidant, Antibacterial and Catalytic Studies. Nano Biomed. Eng., 2020, I2(3): 214-226.

DOI: 10.5101/nbe.v12i3.p214-226.

\begin{abstract}
Green synthesis of silver nanoparticles (Ag NPs) by both ripe and unripe fruit extract was carried out by an important medicinal plant Tinospora cordifolia. The ripe and unripe fruit extract mediated bioinspired Ag NPs showed surface plasmon resonance (SPR) band at 431 and $421 \mathrm{~nm}$ respectively and confirmed the formation of Tc-Ag NPs. The functional groups of bioactive components of ripe and unripe fruits were identified which reduced silver nitrate to silver ions by Fourier-transform infrared spectroscopy (FTIR). The size distribution of biosynthesized Tc-Ag NPs of ripe and unripe was determined by particle size analyzer which revealed that the $\mathrm{Z}$ average of Tc-Ag NPs was around 30$35 \mathrm{~nm} \pm 1 \mathrm{~nm}$ and $30-35.8 \mathrm{~nm} \pm 1 \mathrm{~nm}$ with an $Z$ average of 25.9 and $28.5 \mathrm{~nm}$ respectively. Tc-Ag NPs exhibited stability due to its high negative zeta potential for both ripe and unripe fruit extract mediated Tc-Ag NPs as of -27.2 and -24.6 mV. Tc-Ag NPs were used to evaluate the antibacterial, antioxidant and catalytic activities. The Tc-Ag NPs revealed good antimicrobial activity. Antibiotic erythromycin was used as a standard in the present study. The Tc-Ag NPs of both ripe and unrippen fruits disclosed greater free radical scavenging efficacy which proved to be potent antioxidant agents and also exhibited potential catalytic activity by converting 4 nitro-phenol to 4 amino phenols at rapid pace. It was concluded that the Tc-Ag NPs synthesized by ripe and unripe fruits almost showed similar results, and so both of them proved to have excellent multifunctional biomedical properties.
\end{abstract}

$\overline{\text { Keywords: Tinospora cordifolia; Fruit mediated green synthesis; Spectral characterization; }}$ Antimicrobial activity; Catalytic activity studies

\section{Introduction}

The physical and chemical properties of metallic nanoparticles (NPs) have drawn interest in medicine and other fields for their potential applications in biomedical sciences to be studied. The use of noble metals for the development of nanoparticles with fast and consistent methods, within a short period is the key aspect of nanotechnology. The most common metal nanoparticles are prepared from noble metals like platinum, gold, palladium and silver. Among the noble metal nanoparticles, silver nanoparticles (Ag NPs) have 
drawn major attention by various research scientists in the $21^{\text {st }}$ century due to their versatile applications in biomedical sciences and various branches of physical and chemical sciences including material sciences for the development of various applications like biosensors, catalyst, drug delivery, photonics and electronic sensors and potent antimicrobial agents [15]. Presently the development of new materials and the investigation into their properties have becomes a major thrust area in nanotechnology. Nanotechnology is an emerging technology which has incredible applications in biology, chemistry, physics, material science and medicine. Hence, the development of ecofriendly processes for biosynthesis of nanoparticles without employing any toxic chemicals is most essential [6, 7].

Green synthesis of metallic nanoparticles especially nano silver has increased significantly for the past 10 years because silver is relatively more affordable than platinum, gold and palladium. Biosynthesis of metallic silver nanoparticles has inspired many upcoming researchers to develop various green methods using plant extracts and microorganisms. Plant extracts have been widely used since they are easily available everywhere in different areas and available in bulk quantities, whereas the synthesis of nanoparticles by using various microorganisms like bacteria, fungi, yeast etc. needs laborious, expensive and sterile conditions. Hence, green synthesis of silver nanoparticles using various parts of plants like root, bark, stem, leaf, flower, fruit, whole plant has been reported by various scientists, and the plants include Casia alata, Ceolosious aromaticus, Ficus roots, Glycoriza glabra, Terminellia bellarica, Indigofera hirsuta L, Allmanda Cathartica L. Latex and Andrographis serpyllifolia [8-15]. It is well known that the metal ions bind to plant metabolites and they also act as reducing and stabilising agents. Plant metabolites which include flavinoids, polyphenols, sugars, phenolic acids, alkaloids, terpeniods, enzymes and proteins can reduce the metal ions yielding nanoparticles.

Silver has been used in many traditional and Ayurveda medicines since ancient times and therefore has attracted attention as an antimicrobial agent. Silver nanoparticles have proved to be more efficient antimicrobial agents against bacteria, fungi, viruses and other eukaryotic organisms. For the past 2 decades, most of the human pathogens especially bacteria have developed resistant against most of the antibiotics. So it is highly essential to find out a suitable solution for these problems [16-20].

Tinospora cordifolia (Willd.) Miers ex Hook. F and Thoms belongs to the Menispermaceae family and is commonly known as "Amrita" or "Guduchi" [21]; it is an important drug of Indian Ayurvedic system. These plant species are endemic and commonly available throughout tropical and sub tropical zones of South India. There are several important medicinal uses of Tinospora cordifolia as a health tonic with alternative diuretic and aphrodisiac properties. It is also used in allergies, malaria, chronic, fever, liver tonic, UTI, diabetes, rheumatism and leprosy [22-26]. Earlier studies on Tinospora cordifolia stem revealed its important role in anti-diabetic regulation by controlling blood glucose which is used as traditional folk medicine in India [27]. The major phyto-constituents of Tinospora cordifolia stem are Alkaloids, tannins, cardiac glycosides, flavoinoids, saponins, steroid and glycosides which are responsible for anti-diabetic activity. Tinospora cordifolia extracts have also been reported to have excellent free radicals scavenge activity. Especially alkaloids of Tinospora cordifolia such as choline, tionosporin, isocolumbin palmatine, tetrahydropalmatine and magnoflorine are responsible for major anti-oxidant activity [28]. The stem and leaf extracts of Tinospora cordifolia also proved to be effective in hepatoprotective activity induced by lead nitrate toxicity [29]. The extracts of Tinospora cordifolia also have very good immunomodulatory properties and also cytotoxic effects. The major bioactive compounds like 11-hydromustakone, $\mathrm{N}$-methyl-2-pyrrolidine, $\mathrm{N}$-formylannonain, cordifoliaside, A magnoflorine, and tinocordiside are responsible for several immunomodulatory, cytotoxic, anti tumor and antioxidant activities [30-32]. Extensive investigations have been done on different parts of medicinal plant T.cordifolia, but so far green synthesis of silver nanopaticles by using fruit extract of $T$. cordifolia was not reported.

The present study was carried out to biosynthesize the silver nanoparticles using ripe and unripe fruit extract of Tinospora cordifolia which were collected from Talakona forest region, Chittoor district. Earlier reports on green synthesis of Ag NPs using leaf, bark, stem, flowers extracts of Tinospora cordifolia were done. But nobody reported fruit mediated biosynthesis of Ag NPs so far. In this study, aqueous extract of ripe and unripe fruit was used to synthesize Tc-Ag NPs which were spectrally characterized, with their antioxidant, antibacterial and catalytic activities having 
been studied.

\section{Experimental Materials and chemicals}

Glassware (Borosil), Whatman No. 1 filter paper, silver nitrate (Sigma, Supplier Sigma Bangalore), nutrient agar, nutrient broth (Himedia), DPPH (Sigma), potassium bromide (Sigma), antibiotic discs (Himedia) and 4 nitro phenol (Fisher Scientifics, AR grade), and sodium borohydride (Fisher Scientifics, AR grade).

\section{Collection of Tinospora cordifolia fruit}

The fruits of Tinospora cordifolia both ripe and unripe were collected from Talakona forest region of Chittoor district, Andhra Pradesh, India in October and November 2018. As per our knowledge, the fruits are not commercially available; they are naturally available in hilly areas in and around Chittoor district. The fruits were used freshly as soon as they were collected for the experiment, whereas the remaining fruits were stored at room temperature of $23^{\circ} \mathrm{C}$ in our research lab.

\section{Preparation of Tinospora cordifolia fruit extract}

$10 \mathrm{~g}$ of ripe and unripe T. cordifolia fruits were taken and washed with distilled water. They were grinded into fine paste by using sterile motar and pestle. After grinding the fruits completely, $50 \mathrm{~mL}$ of sterile Milli Q water was added to the paste and the experimental samples were prepared. The samples were filtered by using Whatman No.1 filter paper to get clear extract solution. The filtered solution obtained was the source of aqueous extract for biosynthesis of green silver nanoparticles (Fig. 1(a)-(b)).

\section{Biosynthesis of Ag NPs}

To $1 \mathrm{~mL}$ of ripe and unripe fruit extract, solutions were taken separately in sterile boiling test tubes and made up to $5 \mathrm{~mL}$ volume with sterile distilled water. 10 $\mathrm{mL}$ of $\mathrm{AgNO}_{3}(0.002 \mathrm{mM})$ was added, and the samples were heated in a water bath at $70{ }^{\circ} \mathrm{C}$ for 30 min until the color changed. The color of less unripe fruit extract changed to light brown, and the pale pink color of ripe fruit extract changed to dark brown. This indicated the reduction of both ripe and unripe fruit extract to Ag NPs. The results are shown in Fig. 2(a)-(d).

\section{Purification of Tc-Ag NPs}

The solution containing Tc-Ag NPs was centrifuged at $15,000 \mathrm{rpm}$ for $15 \mathrm{~min}$ to obtain the green Tc-Ag NPs pellet. The Tc-Ag NPs pellet was re-dispersed

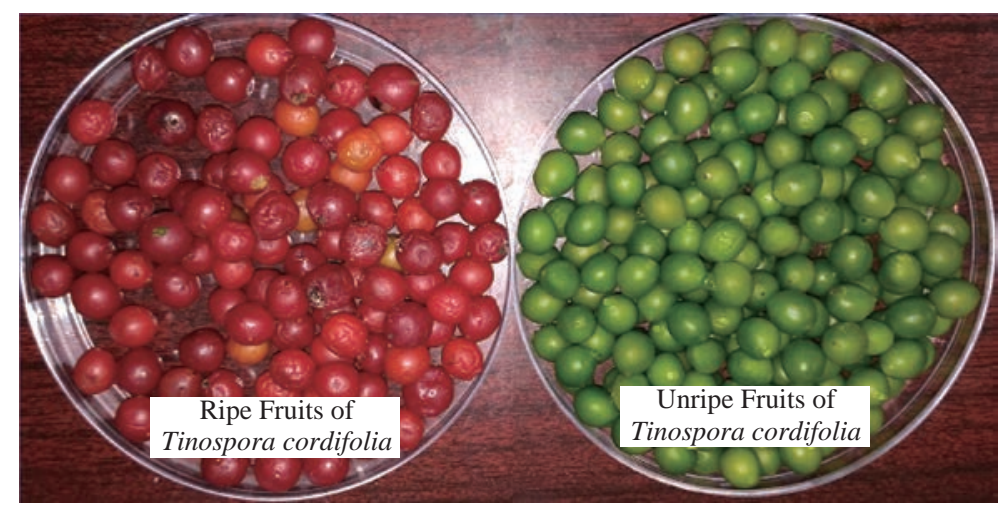

(a)

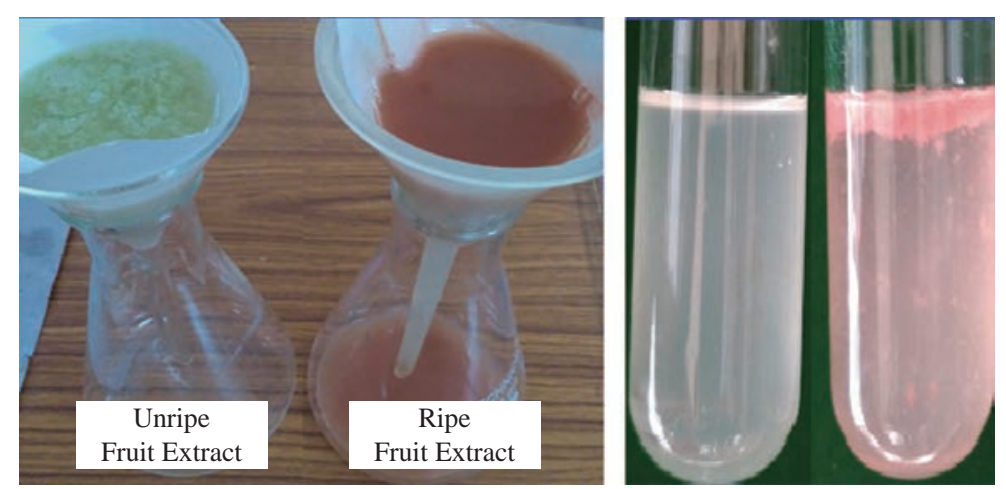

(b)

Fig. 1 (a) Ripe and unripe fruits of Tinospora cordifolia; (b) Filtration of aqueous extract of ripe and unripe fruits of Tinospora cordifolia, and aqueous extract of ripe and unripe fruits of Tinospora cordifolia. 


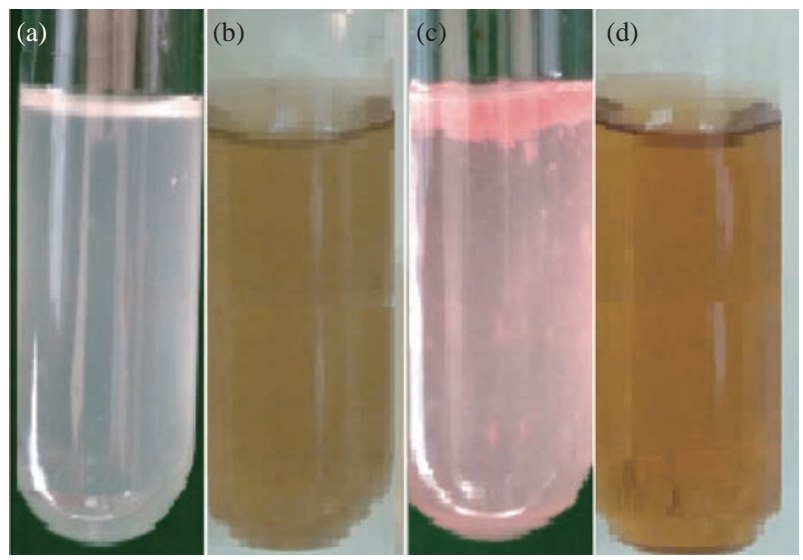

Fig. 2 (a) Extract of unripe fruits of Tinospora cordifolia; (b) Tc-Ag NPs of unripe fruits of Tinospora cordifolia; (c) Extract of ripe fruits of Tinospora cordifolia; (d) Tc-Ag NPs of ripe fruits of Tinospora cordifolia.

in $25 \mathrm{~mL}$ of sterile Milli Q water and centrifuged again at $15000 \mathrm{rpm}$ for $15 \mathrm{~min}$ to get rid of any biological molecules. The process of centrifugation and re-dispersion in sterile Milli Q distilled water was repeated thrice to obtain pure green Tc-Ag NPs and to get rid of the unbound plant extract residues. The purified green Tc-Ag NPs pellets were then used for successive studies including Fourier-transform infrared spectroscopy (FTIR), particle size analysis, zeta potential analysis, energy-dispersive $\mathrm{X}$-ray spectroscopy (EDX), X-ray diffraction (XRD) and other advanced spectroscopic analyses.

\section{Spectral characterization of Tc-Ag NPs}

The biosynthesized Tc-Ag NPs with the ripe and unripe fruit extract of $T$. cordifolia were analysis using Nanodrop 800 (UV-visible spectrophotometer, Thermo Scientific). The optical density (OD value) of the TcAg NPs was recorded at 220-750 nm wave length range by periodically sampling $1-3 \mu \mathrm{L}$ of sample and the reaction of the sample was carried out at room temperature on the Nanodrop spectrophotometer at the resolution of $1 \mathrm{~nm}$. FTIR analysis was carried out by using Alpha T model FTIR spectrophotometer, Bruker Company. The purified pellets of Tc-Ag NPs and control fruit extract were used in the FTIR analysis. The particle size and zeta potential analysis was carried out by using Horiba Nanopartica SZ-100 Nanoparticle analyzer (DST PURSE Centre, SVU, Tirupati). The particle size was detected by dynamic light scattering (DLS) of nanoparticles present in the solution and the zeta potential was also carried out to find out the surface charge present on the Ag NPs. EDX analysis was also carried out to find out the exact percentage of silver ions and elements present in the biosynthesized
Tc-Ag NPs. (VIT, Vellore). The shape and size of the Tc-Ag NPs was determined by using Transmission electron microscopy studies (TEM- FEI Tecnai F12, Philips Electron Optics, Holland) operated at 100 $\mathrm{kV}$ (VIT, Vellore). The size of the biosynthesized Ag NPs was calculated by using SIS imaging software (Munster, Germany).

\section{DPPH antioxidant activity of Tc-AgNPs}

The antioxidant activity of the Tc-Ag NPs was measured by 2,2-diphenyl-1-picrylhydrazyl (DPPH) radical scavenging assay [33]. $4 \mathrm{mg}$ of DPPH was dissolved in $100 \mathrm{~mL}$ of methanol and stored at $20^{\circ} \mathrm{C}$. From the stock solution, $2 \mathrm{~mL}$ of solution was added to $1 \mathrm{~mL}$ methanol solution containing test samples of $T$. cordifolia fruit extract and Tc-Ag NPs of both ripe and unripe fruits at different concentrations of $25,50,75$ and $100 \mu \mathrm{g} / \mathrm{mL}$. The DPPH free radical scavenging activity (RSA) was measured at $517 \mathrm{~nm}$. Ascorbic acid was used as standard in the present study. The $\mathrm{IC}_{50}$ values of antioxidant activity of all samples including the standard ascorbic acid were calculated in the present study. The percentage of free radical scavenging activity was calculated by using the following equation:

RSA (\%) $=$ (Control absorbance - Sample absorbance) / Control absorbance) $\times 100$.

\section{Anti-bacterial activity of Tc-Ag NPs}

The anti-bacterial activity of Tc-Ag NPs was studied against different pathogenic bacteria such as E. coli (Gram-negative), Klebsialla pneumonia (Gramnegative), Staphylococcus aureus (Gram-positive), and Bacillus cereus (Gram-positive) by Kirby Bauer disc diffusion method. Freshly prepared bacterial culture of all the above bacterial samples was grown in sterile nutrient broth for overnight at $37{ }^{\circ} \mathrm{C} .100 \mu \mathrm{L}$ of respective microbial cultures were spread on nutrient agar plates, sterile Whatman Grade 1 filter paper discs were placed on nutrient agar plates at respective places. The bio-synthesized green Tc-Ag NPs of ripe and unripe fruits' extract and Tc-extract of ripe and unripe fruits were added onto the sterile discs with the help of micropipette at different concentrations of 15 and 30 mcg, and Erythromycin E-15 15 mcg disc was used as standard antibiotic. The nutrient agar plates loaded with Tc-Ag NPs and antibiotic were incubated at $37^{\circ} \mathrm{C}$ for overnight.

\section{Catalytic activity of Tc-Ag NPs for reduction of 4 nitro phenol to 4 amino phenol}

The catalytic activity of Tc-Ag NPs of unripe fruit 
extracts was detected by taking 2,000 $\mu \mathrm{L}$ 2-nitrophenol and $750 \mu \mathrm{L} \mathrm{Na}{ }_{2} \mathrm{BH}_{2}$; immediate readings were taken in UV-Vis spectrophotometer (Nanodrop 8000). The catalytic reaction was continued by adding $250 \mu \mathrm{L}$ of Tc-Ag NPs and the readings were recorded for every 3 min up to $15 \mathrm{~min}$. Finally, a graph was plotted for catalytic activity.

\section{Results and Discussion Ultraviolet-visible analysis of Tc-Ag NPs}

The green synthesized Tc-Ag NPs were measured using UV-visible Nanodrop 8000 spectrophotometer from 220 to $750 \mathrm{~nm}$ wavelength range, and the surface Plasmon resonance (SPR) spectra of Tc-Ag NPs was obtained at $447 \mathrm{~nm}$ for ripe fruit extract (Fig. 3(a)) and $423 \mathrm{~nm}$ for unripe fruit extract (Fig. 3(b)). The SPR was due to the presence of free electrons present on the surface of Ag NPs which played a vital role on the size of the bio-synthesized nanoparticles [34]. Previous reports revealed that the nanoparticles had a SPR range between 390-420 nm, and had small sizes of around $25-50 \mathrm{~nm}$ in diameter. Earlier studies confirmed that the results regarding the size and shape were similar to the bio-synthesized silver nanoparticles [10-12]. Similar results were also reported by other scientists in their recent studies [35, 36].

\section{Fourier-transform infrared spectroscopy analysis of Tc-Ag NPs}

The FTIR spectrum of both ripe and unripe extracts and biosynthesized Tc-Ag NPs with ripe and unripe fruits was carried out. The IR data of ripe fruit extract clearly showed absorption bands at wave values of $3275,2116,1637$ and $682 \mathrm{~cm}^{-1}$ corresponding to $\mathrm{O}-\mathrm{H}$ hydroxyl and the N-H, -C, N-H and C-CI stretches. The Tc-Ag NPs (ripe fruit) showed intensive peaks at 3277, 2354, 2120, 1637 and $667 \mathrm{~cm}^{-1}$ (Fig. 4(a) and (b)), which corresponded to O-H, C-O, N-H, C-CI functional groups. At the same time, the IR spectra of unripe fruit extract and Tc-Ag NPs exhibited different spectral bands at 3281, 2355, 2122, 1637 and $667 \mathrm{~cm}^{-}$ ${ }^{1}$, and $3279,2399,2216,1637,706$ and $632 \mathrm{~cm}^{-1}$, corresponding to $\mathrm{O}-\mathrm{H},-\mathrm{C}, \mathrm{N}-\mathrm{H}$ functional groups. $=\mathrm{C}-$ $\mathrm{H}, \mathrm{C}-\mathrm{CI}$ were found in both extracts and Tc-Ag NPs (Fig. 4(c) and (d)). The result revealed the presence of biologically active compounds responsible for the reduction, capping and stabilization of bio-synthesized Tc-Ag NPs. The fruit extracts consisted of different concentrations of phyto-chemical constituents such as glycosides or sugars, fructose, sucrose, galactose, terpenoid, and saponin. The functional phytoconstituents of both ripe and unripe fruit extracts of $T$. cordifolia were responsible for capping and stabilizing the reduced nanoparticles. Similar results were also observed where the free hydroxyl groups of plant and fruit extracts were very suitable for the reduction of silver ions [37].

\section{Particle size analysis of Tc-Ag NPs}

The particle size of Tc-Ag NPs of both ripe and unripe fruits was determined by nanoparticle size analyzer by intensity and laser diffraction method. The results revealed that the biosynthesized $\mathrm{Tc}-\mathrm{Ag}$ NPs were of varied sizes in nature ranging from 30 $35 \mathrm{~nm} \pm 1 \mathrm{~nm}$ to $30-35.8 \mathrm{~nm} \pm 1 \mathrm{~nm}$ with $\mathrm{Z}$ average
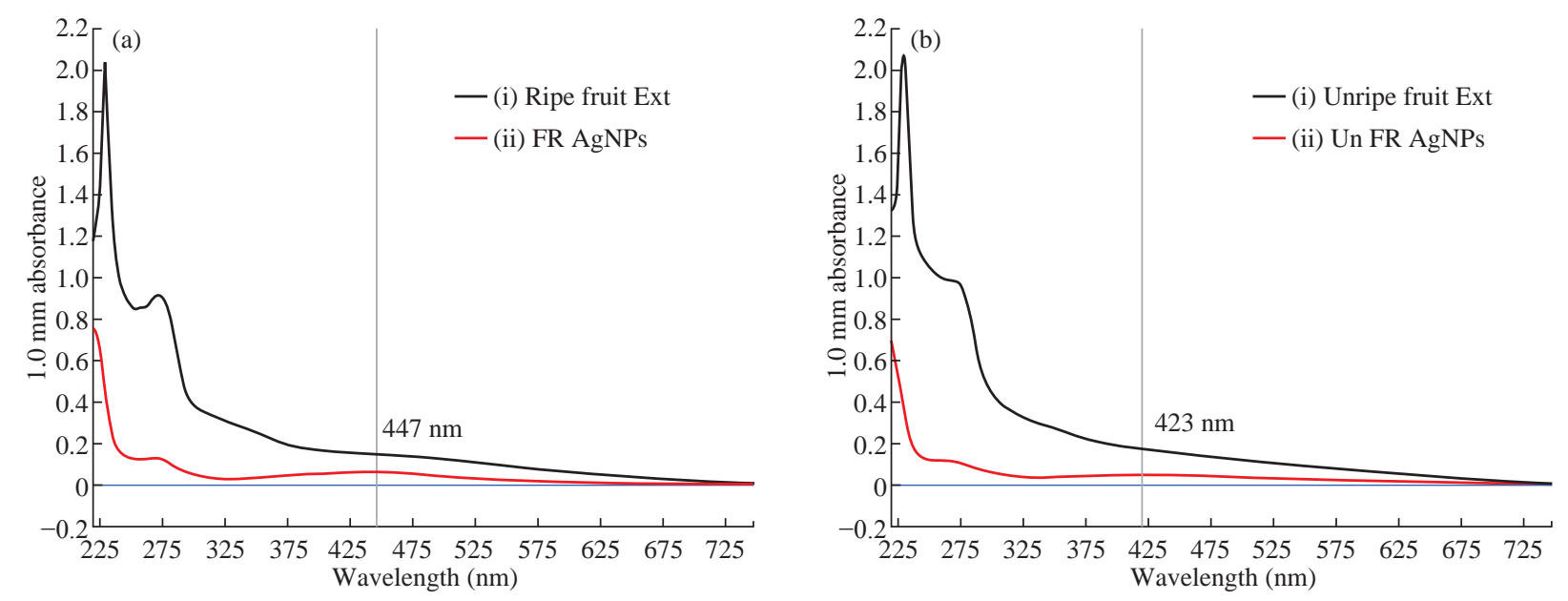

Fig. 3 (a) (i) UV-visible absorption spectra of T. cordifolia ripe friut extract; (ii). UV-visible absorption spectra of Tc-Ag NPs synthesized from T. cordifolia ripe fruit extract with $2 \times 10^{-3} \mathrm{M}$ silver nitrate. (b) (i) UV-visible absorption spectra of T. cordifolia unripe fruit extract; (ii) UV-visible absorption spectra of Tc-Ag NPs synthesized from T. cordifolia unripe fruit extract with $2 \times 10^{-3} \mathrm{M}$ silver nitrate. 

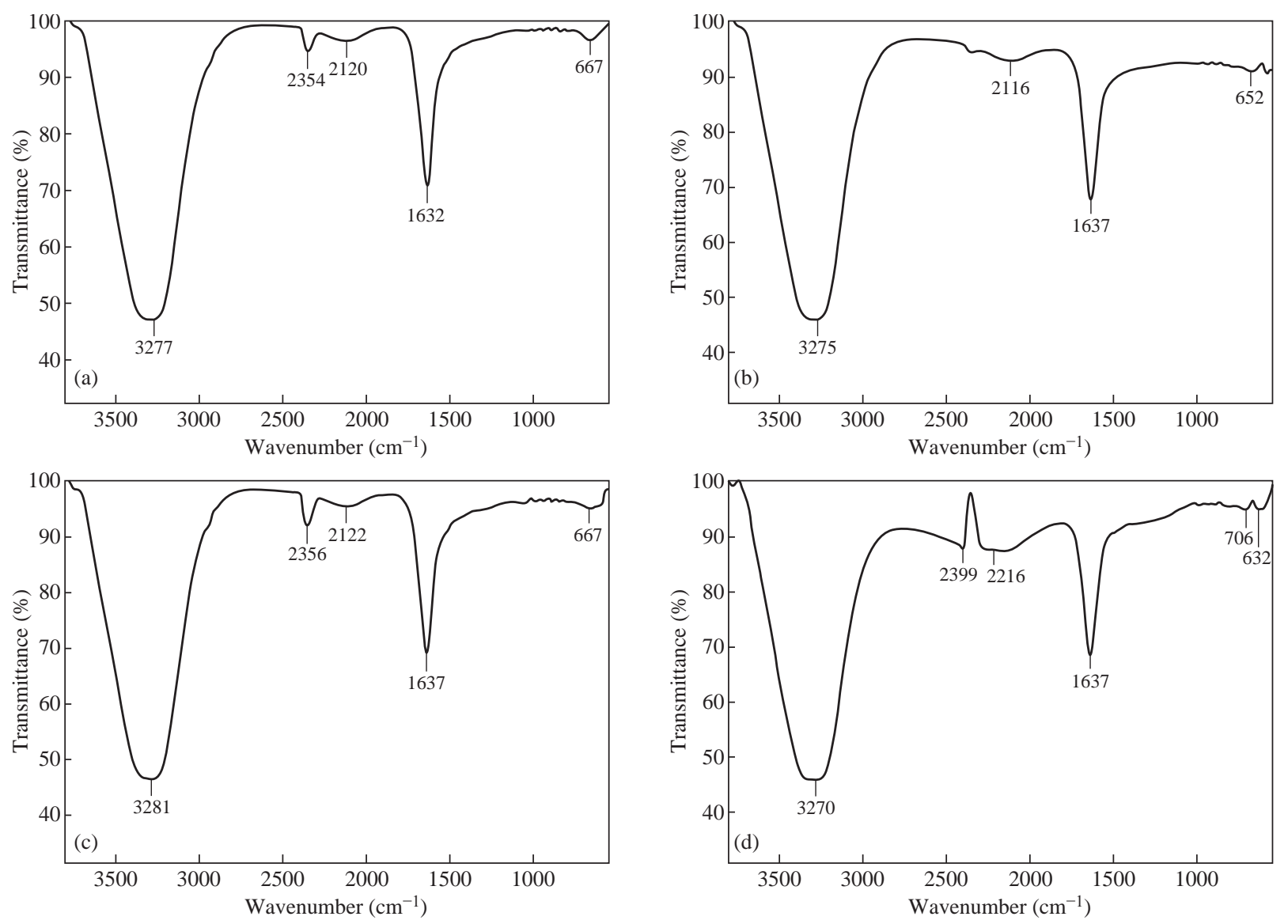

Fig. 4 (a) and (b) FTIR spectra of T. cordifolia ripe fruit extract and Ag NPs biosynthesized using ripe fruit extract. (c) and (d) FTIR spectra of T. cordifolia unripe fruit extract and $\mathrm{Ag}$ NPs biosynthesized using unripe fruit extract.

of 25.9 and $28.5 \mathrm{~nm}$ respectively (Fig. 5(a) and (b)). It clearly revealed that the particles were poly dispersed in nature. In our present study, it was also clearly seen that the size of Tc-Ag NPs was similar to that of transmission electron microscopy (TEM) results with sight variation in the size $\pm 3 \mathrm{~nm}$ to $\pm 5 \mathrm{~nm}$ smaller than the particle size analysis. The earlier reports clearly explained that the size measured through DLS was not the exact size of the nanoparticles, due to the presence of hydration layer around the Ag NPs and it was measured through hydrodynamic radius. The hydration layer of bioactive components acted as stabilizing and capping agents of Ag NPs [37, 38].

\section{Zeta potential analysis of Tc-Ag NPs}

The biosynthesized Tc-Ag NPs were found to have high negative zeta potential of $-27.2 \mathrm{mV}$ with ripe fruit extract and $-24.6 \mathrm{mV}$ with unripe fruit extract (Fig. 5(c) and (d)), indicating the repulsion among the green Tc-Ag NPs which increased the stability of the formulation. It was evident that the Tc-Ag NPs were poly dispersed in nature due to its high negative zeta potential. It is known that the electrostatic repulsive force between the nanoparticles results in the prevention of agglomeration helpful for long term stability [8-11].

\section{Transmission electron microscopy analysis of Tc-Ag NPs}

Further studies were continued to determine the structural properties such as size and shape of biosynthesized Tc-Ag NPs by using the ripe fruit extract mediated nanoparticles. The images taken at different magnifications revealed that Tc-Ag NPs (ripe fruit extract) were spherical in shape with their size ranging from 10 to $17 \mathrm{~nm} \pm 10 \mathrm{~nm}$. The scale bar of TEM micrographs was measured at $50 \mathrm{~nm}$ (Fig. 6(a)(c)).

\section{Energy dispersive X-ray analysis of Tc-Ag NPs}

Energy dispersive X-ray analysis (EDX) analysis revealed very strong signals for silver, moderate signals for copper, and weak signals for other elements like oxygen and carbon, which might originate from the biomolecules that were bound to the surface of the Ag NPs, indicating the reduction of silver to elemental silver (Fig. 7). The elemental silver was more than $68.48 \%$ and the remaining $31.52 \%$ was copper, 
Calculation results

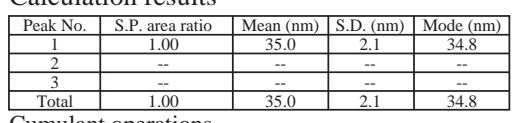

Cumulant operations

Z-average: $25.9 \mathrm{~nm}$

PI: 2.040

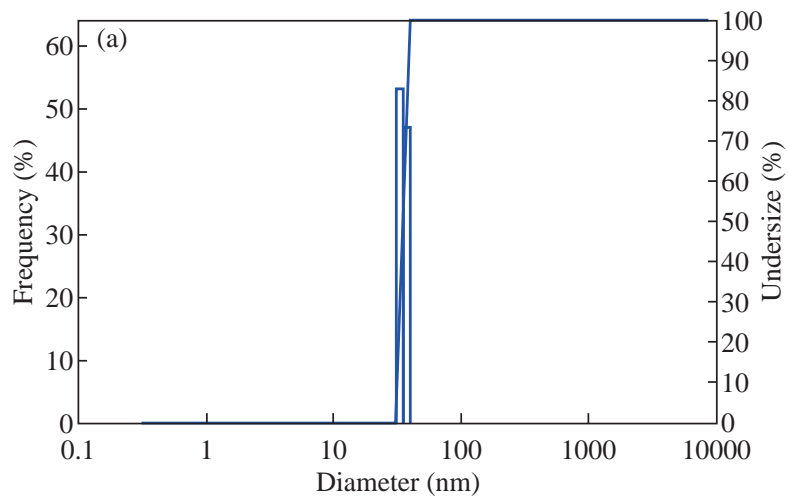

Calculation results

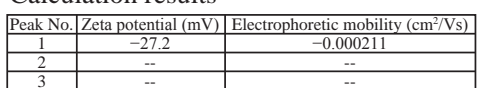

Zeta potential (mean): $-27.2 \mathrm{mV}$

Electrophoretic mobility mean: $-0.000211 \mathrm{~cm}^{2} / \mathrm{Vs}$

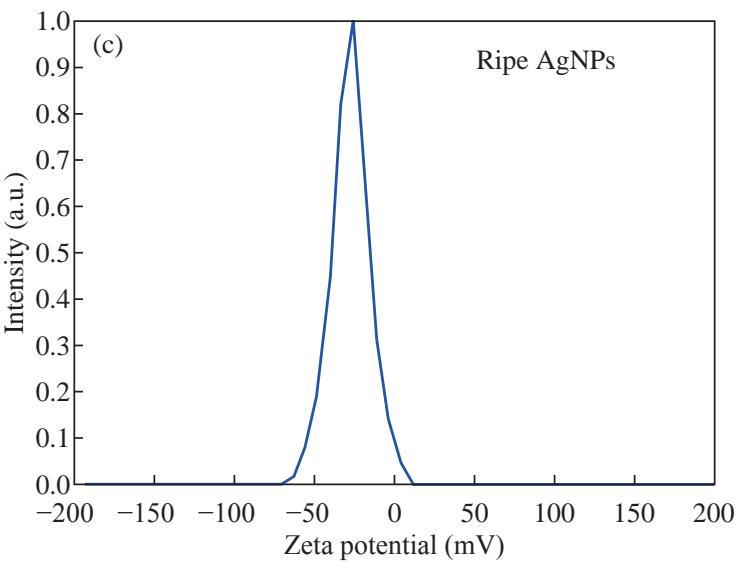

Calculation results
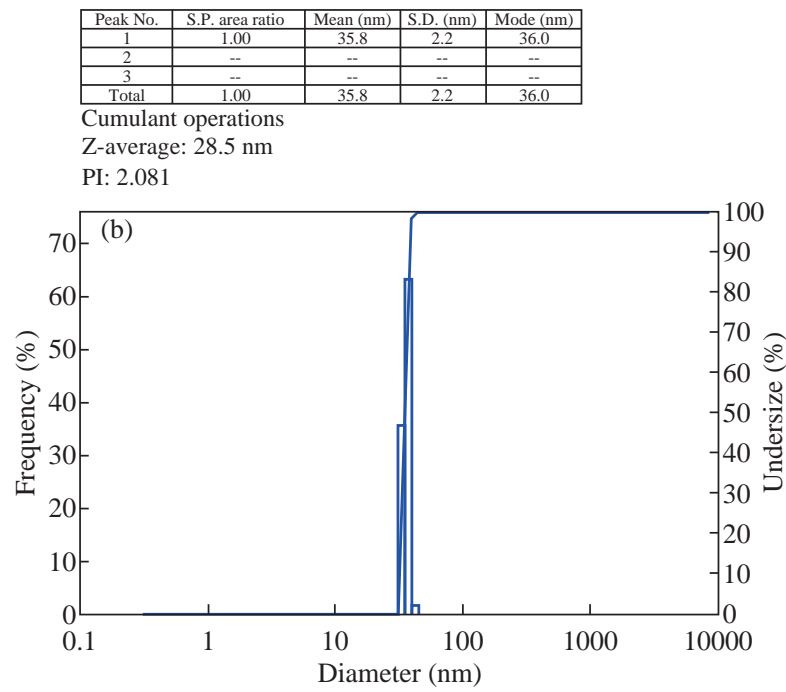

Calculation results

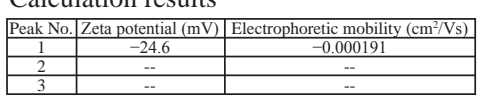

Zeta potential (mean): $-24.6 \mathrm{mV}$

Electrophoretic mobility mean: $-0.000191 \mathrm{~cm}^{2} / \mathrm{Vs}$

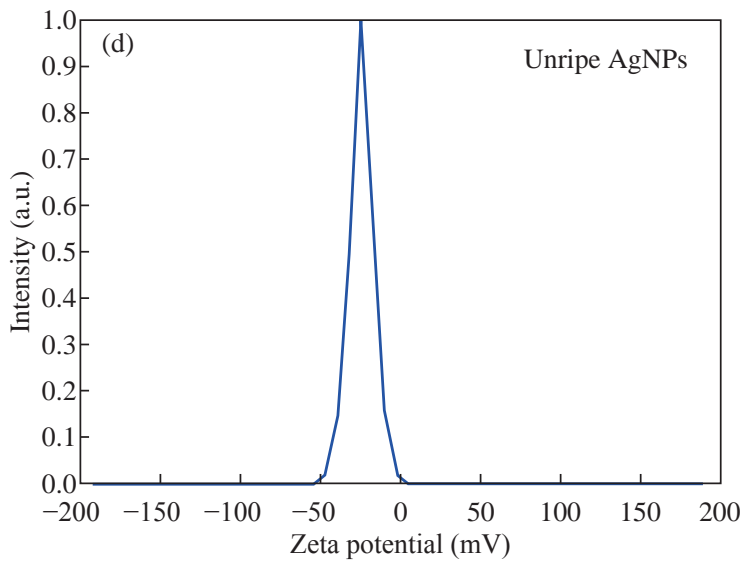

Fig. 5 (a) and (b) Particle size of Ag NPs biosynthesized using both T. cordifolia ripe and unripe fruit extract; (c) and (d) Zeta potential of Ag NPs biosynthesized using both $T$. cordifolia ripe and unripe fruit extract.

given that the analysis was carried out by coating our sample on a carbon coated copper grid. Metallic silver nanocrystals generally showed typical optical absorption peak, approximately at $3 \mathrm{keV}$ due to surface Plasmon resonance. [39-41]. No peaks for silver compounds were observed, which indicated the silver compound had been reduced completely to Ag NPs as determined by the spectrum.

\section{DPPH antioxidant activity of Tc-Ag NPs}

The natural antioxidants are believed to be very important for human diet, especially in relation to oxidative stress prevention of various diseases including atherosclerosis, neurodegenerative diseases, rheumatoid arthritis, age-related degeneration and cancer initiation. It is well-known that antioxidants including enzymes and other substances such as vitamin $\mathrm{C}$, vitamin $\mathrm{E}$ and beta carotene are capable of counteracting the damaging effects of oxidation. Especially the plant parts such as leaves, bark roots and fruits contain bioactive compounds which have good antioxidant activity. Several scientists used different medicinal plant parts for the synthesis of metal nanoparticles and studied their antioxidant and other biomedical applications $[42,43]$. In the present study, the antioxidant activity of the biosynthesized TcAg NPs by ripe and unripe fruit extracts was studied by using DPPH method. The scavenging ability was quantified using spectrophotometer by taking optical density (O.D) at $517 \mathrm{~nm}$. The percentage of antioxidant activity of ripe and unripe Tc-Ag NPs and ripe and unripe fruit extracts was calculated; results 

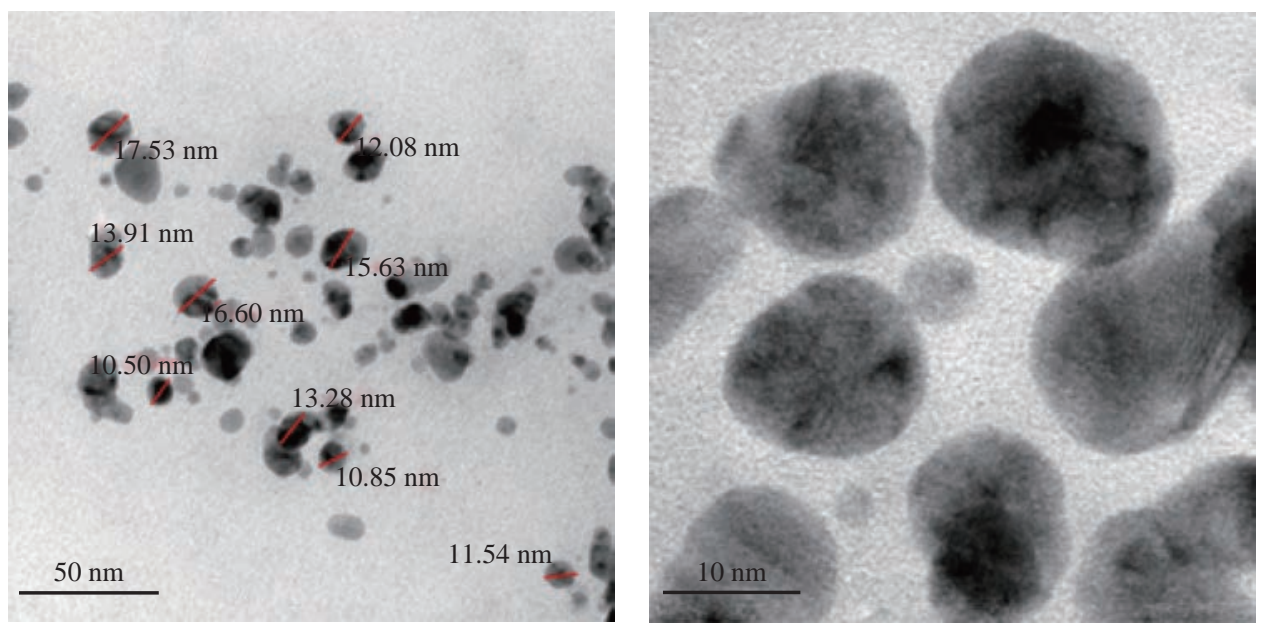

(a)
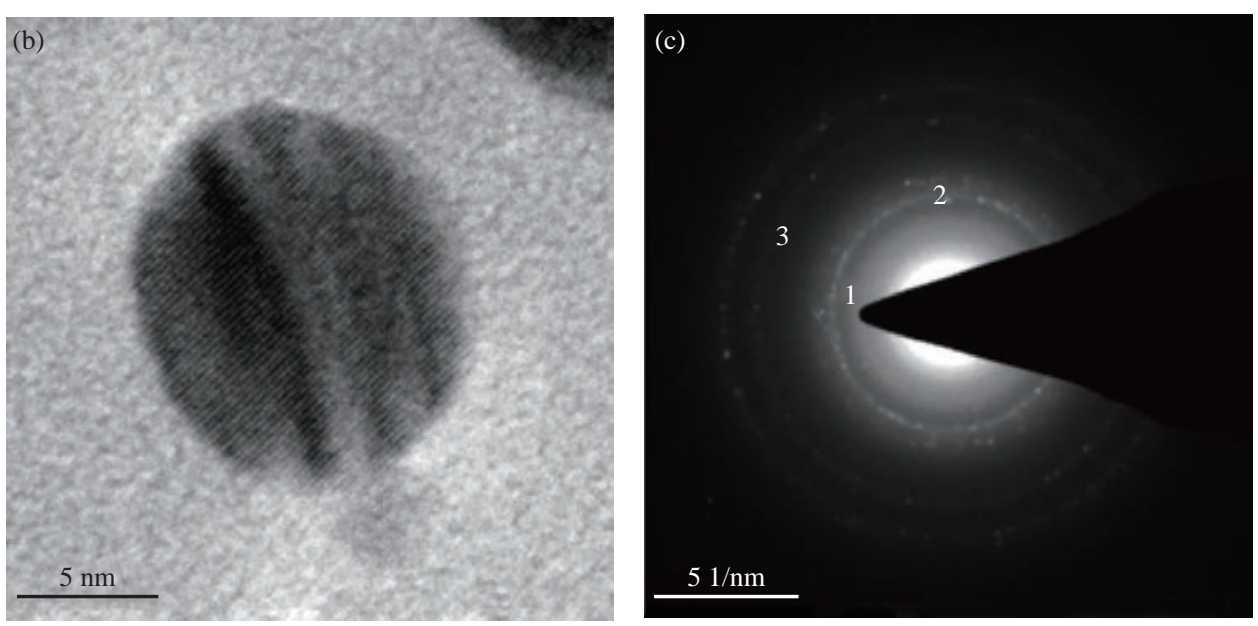

Fig. 6 (a) TEM analysis showed spherical shaped Tc-Ag NPs (bar = $50 \mathrm{~nm}$ ); (b) Single spherical Tc-Ag NPs at $490 \mathrm{Kv}$ magnification; (c) SAED pattern of Tc-Ag NPs showing diffraction rings.

are tabulated in Table. 1 and illustrated in Fig. 8. The results of antioxidant activity for both ripe and unripe fruit extracts and ripe and unripe Tc-Ag NPs increased with the increase in concentration from 25 to $100 \mu \mathrm{g} /$ $\mathrm{mL}$. The ripe Tc-Ag NPs showed highest free radical scavenging activity, i.e. $65.52 \%$, followed by unripe Tc-Ag NPs. The antioxidant activity of extracts was lower than the Tc-Ag NPs, whereas the antioxidant activity of Tc-Ag NPs was lower than the standard ascorbic acid. However, the Tc-Ag NPs showed very good or almost equivalent free radical scavenging activity. The free radical scavenging activity of biosynthesized Tc-Ag NPs might be due the bioactive components present on the surface of the nanoparticles and they were ready to give up hydrogen atom from their hydroxyl groups to free radicals and form stable phenoxy radicals. Similar results were also reported by other scientist using aqueous extracts of plants and biosynthesized Ag NPs [44]

\section{Antimicrobial activity of Tc-Ag NPs}

To reveal the biomedical importance of the TcAg NPs biosynthesized from Tinospora cordifolia ripe and unripe fruit extracts, antimicrobial activity was performed against 4 bacterial species of grampositive Staphylococcus aureus, Bacillus cereus and

Table 1 DPPH activity

\begin{tabular}{ccccc}
\hline & \multicolumn{3}{c}{ DPPH } \\
\cline { 2 - 5 } & $25(\mu \mathrm{g} / \mathrm{mL})$ & $50(\mu \mathrm{g} / \mathrm{mL})$ & $75(\mu \mathrm{g} / \mathrm{mL})$ & $100(\mu \mathrm{g} / \mathrm{mL})$ \\
\hline Unripe extract & 18.34 & 28.02 & 39.12 & 48.32 \\
Unripe Ag NPs & 25.06 & 31.45 & 44.28 & 59.02 \\
Ripe extract & 30.22 & 37.18 & 51.09 & 62.66 \\
Ripe Ag NPs & 33.03 & 44.15 & 56.05 & 65.6 \\
Ascorbic acid & 53.62 & 64.47 & 72.36 & 56.49 \\
\hline
\end{tabular}




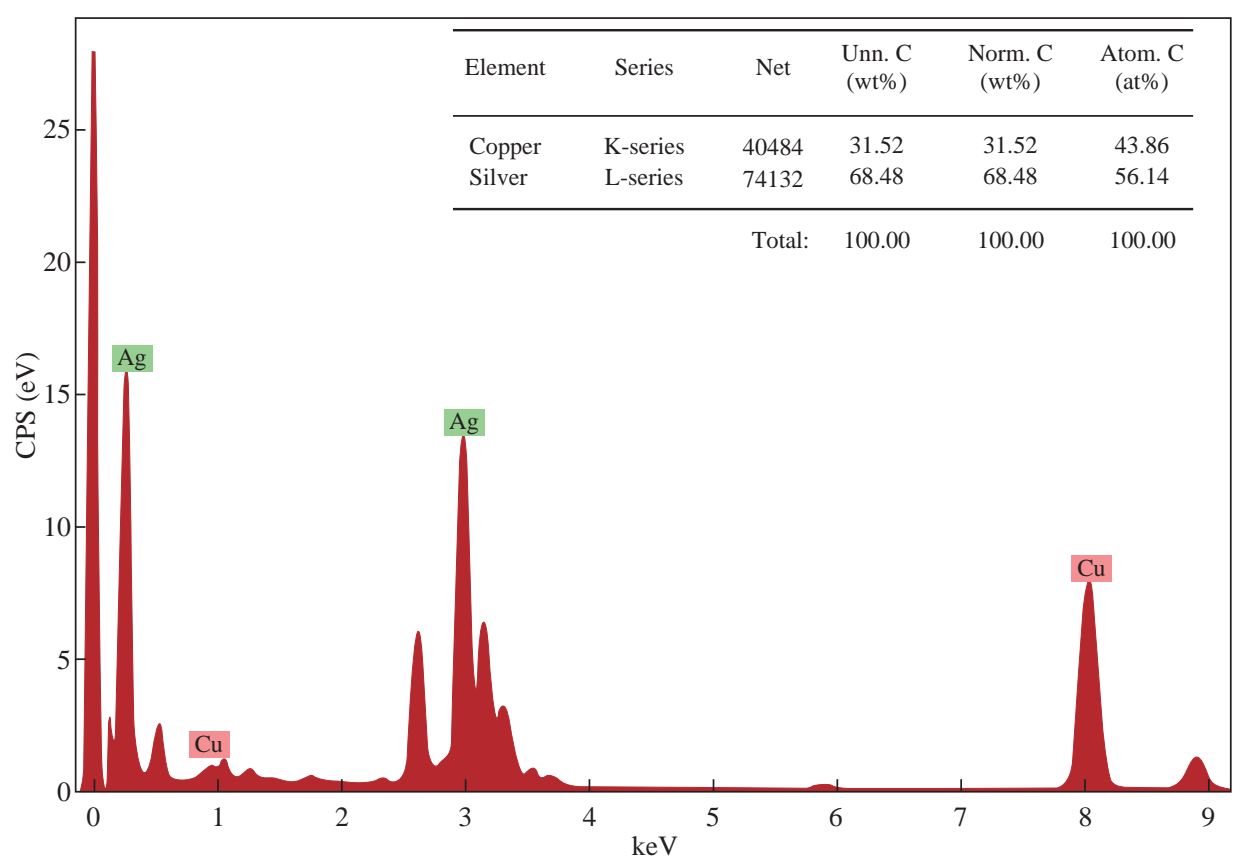

Fig. 7 EDX analysis of Tc-Ag NPs biosynthesized using T. cordifolia ripe fruit extract.

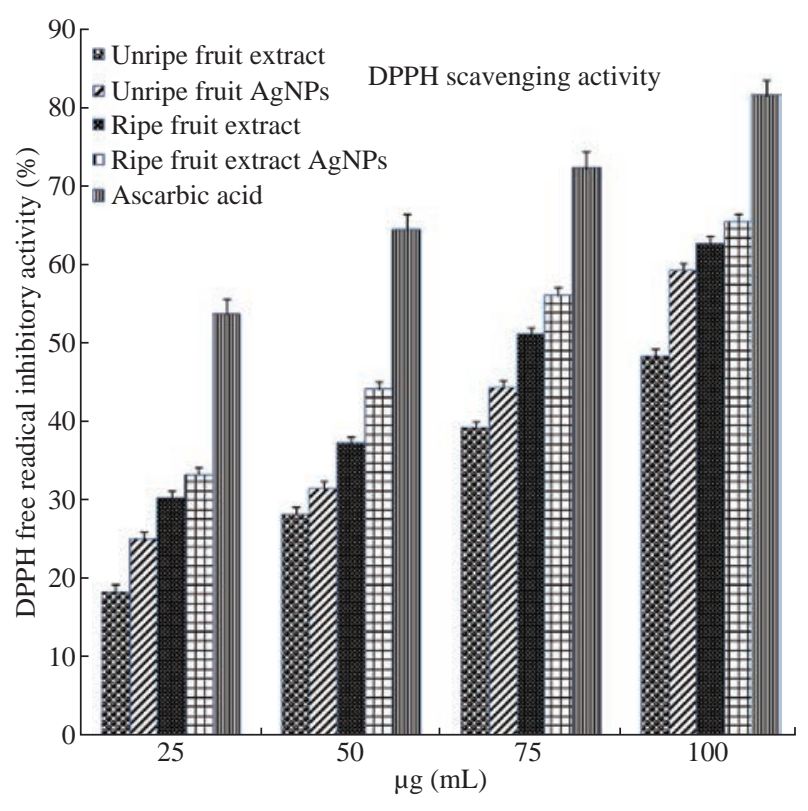

Fig. 8 Antioxidant activity of ripe and unripe Tc-Ag NPs in comparison with standard ascorbic acid.

gram-negative Escherichia coli, Klebsella pneumonia by the Kirby-Bauer disc diffusion method. The bio- synthesized Tc-Ag NPs from Tinospora cordifolia ripe and unripe fruit extracts exhibited good antibacterial activity against gram-positive Bacillus cereus $15 \mathrm{~mm}$ (15 mcg), $20 \mathrm{~mm}(30 \mathrm{mcg}$ ) for ripe Tc-Ag NPs, and $20 \mathrm{~mm}$ (15 mcg), $20 \mathrm{~mm}$ (30 mcg) for unripe TcAg NPs. And in Staphylococcus aureus, the zone of inhibition is as follows: $16 \mathrm{~mm}(15 \mathrm{mcg}), 18 \mathrm{~mm}$ (30 mcg) for ripe Tc-Ag NPs, and for unripe Tc-Ag NPs 16 $\mathrm{mm}$ (15 mcg), $20 \mathrm{~mm}$ (30 mcg). They also exhibited good activity. The zone of inhibition against gramnegative Escherichia coli is as follows: $17 \mathrm{~mm}$ (15 $\mathrm{mcg}$ ), $22 \mathrm{~mm}$ (30 mcg) for ripe Tc-Ag NPs and $16 \mathrm{~mm}$ (15 mcg), $20 \mathrm{~mm}$ (30 mcg) for unripe Tc-Ag NPs. The zone of inhibition for Klebsella pneumonia bacteria is as follows: $16 \mathrm{~mm}(15 \mathrm{mcg}), 20 \mathrm{~mm}(30 \mathrm{mcg})$ for ripe Tc-Ag NPs, and $16 \mathrm{~mm}(15 \mathrm{mcg}), 18 \mathrm{~mm}(30 \mathrm{mcg})$ for unripe Tc-Ag NPs. The results are tabulated in Table 2. Apart from Tc-Ag NPs we also carried out the experiment with negative control, i.e. fruits extracts of both ripe and unripe fruits, but we did not see any zone of inhibition (data not shown). The zone of inhibition

Table 2 Antimicrobial activity

\begin{tabular}{ccccc}
\hline \multirow{2}{*}{ Ag NPs } & \multicolumn{4}{c}{ Inhibition zone $(\mathrm{mm})$} \\
\cline { 2 - 5 } & E. coli & S. aureus & B. cereus & K. pneumoniae \\
\hline Ripe fruit $15 \mathrm{mcg}$ & 17 & 16 & 15 & 16 \\
Ripe fruit 30 mcg & 22 & 18 & 20 & 21 \\
Unripe fruit $15 \mathrm{mcg}$ & 16 & 16 & 20 & 16 \\
Unripe fruit 30 mcg & 20 & 20 & 20 & 17 \\
Antibiotic (Erythromycin) & 32 & 28 & 30 & 31 \\
\hline
\end{tabular}


for standard antibiotic Erythromycin (Himedia SD013 E-15, $15 \mathrm{mcg}$ ) against 4 bacteria is as follows: Grampositive Staphylococcus aureus (28 mm), Bacillus cereus (30 mm), and Gram-negative Escherichia coli (32 mm) and Klebsella pneumonia (31 mm). The TcAg NPs showed a good antibacterial activity against gram-positive and gram-negative bacteria (Fig. 9). The Tc-Ag NPs exhibited good anti-bacterial activity and the antibacterial activity was lower less than that of standard antibiotic Erythromycin (15 mcg). The results were similar to the earlier reports [9-12, 44].

\section{Catalytic activity of Tc-Ag NPs}

The catalytic activity of biosynthesized Tc-Ag NPs by both ripe and unripe fruit extracts was analyzed in the present study. Recently, several research groups have investigated the catalytic reduction of 4-nitrophenol with $\mathrm{NaBH}_{4}$, using a number of noble metals such as $\mathrm{Ag}, \mathrm{Au}, \mathrm{Cu}, \mathrm{Pt}$ and $\mathrm{Pd}$ nanoparticles. Before we investigated the catalytic activity of the unripe biosynthesized Tc-Ag NPs, the catalytic ability of the $\mathrm{NaBH}_{4}$ was examined with aqueous solution of 4-nitrophenol (1.5 mmol in $100 \mathrm{~mL})$, which had a maximum absorption at $319 \mathrm{~nm}$. Immediately freshly prepared aqueous solution of $\mathrm{NaBH}_{4}$ was added. The peak of 4-nitrophenol shifted from 319 to 400 $\mathrm{nm}$ (Fig. 10). This peak was due to the formation of 4-nitrophenolate ions in alkaline condition caused by the addition of $\mathrm{NaBH}_{4}$. The reaction was continued by the addition of unripe Tc-Ag NPs, and the results were recorded. We could clearly see that there was further catalytic reaction and the results were recorded up to $15 \mathrm{~min}$. The result revealed that there was moderate enhancement of catalytic reaction [45, 46].
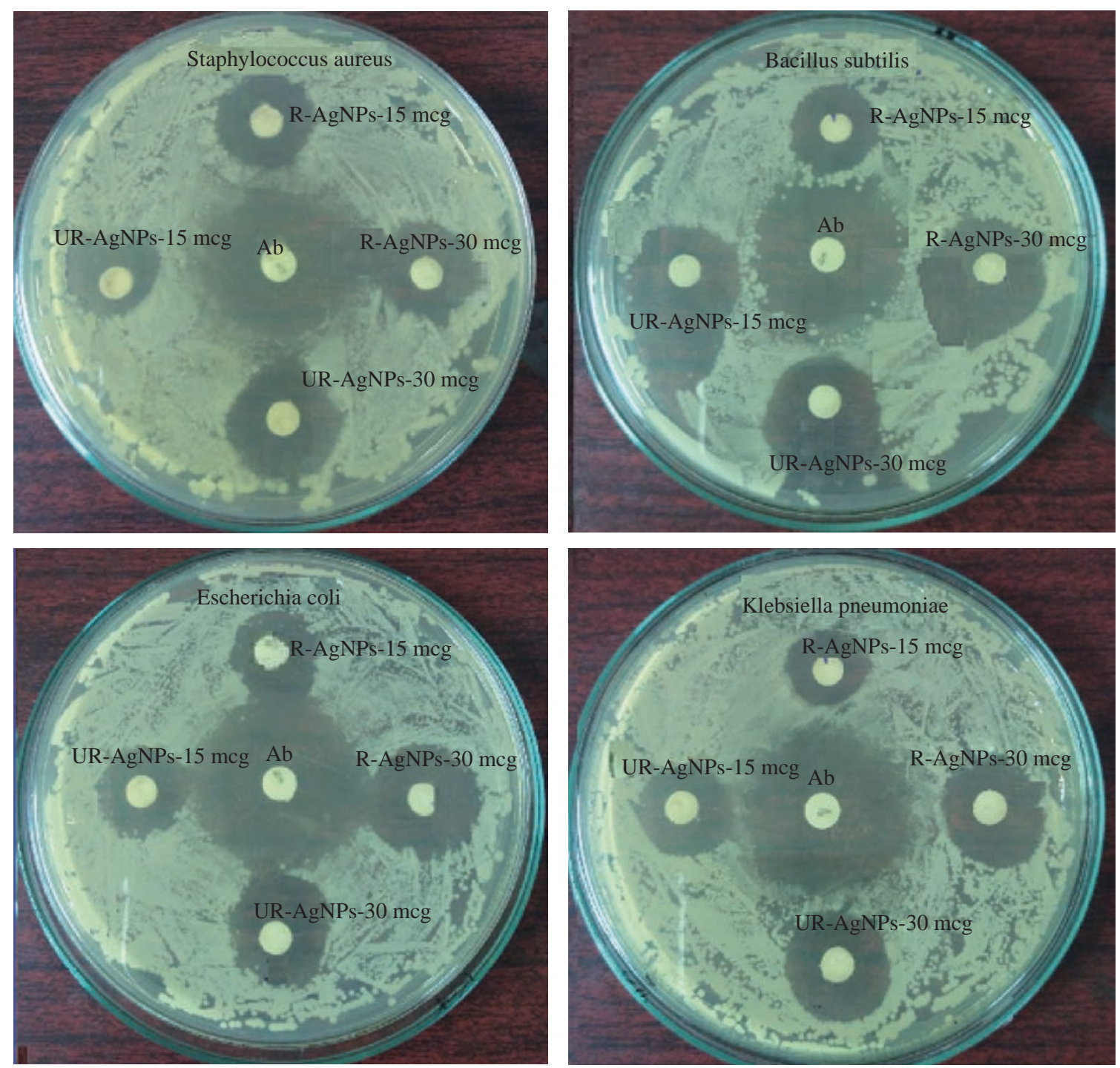

Fig. 9 Antimicrobial activity of the ripe and unripe Tc-Ag NPs against S. aureus, Bacillus cerus, E. coli and K. pneumonia. Inhibition zone was observed by both ripe fruit Ag NPs and unripe fruit Ag NPs at different concentrations of 15 and 30 mcg, compared with standard antibiotic Himedia-SD013 E-15, 15 mcg Erythromycin. 

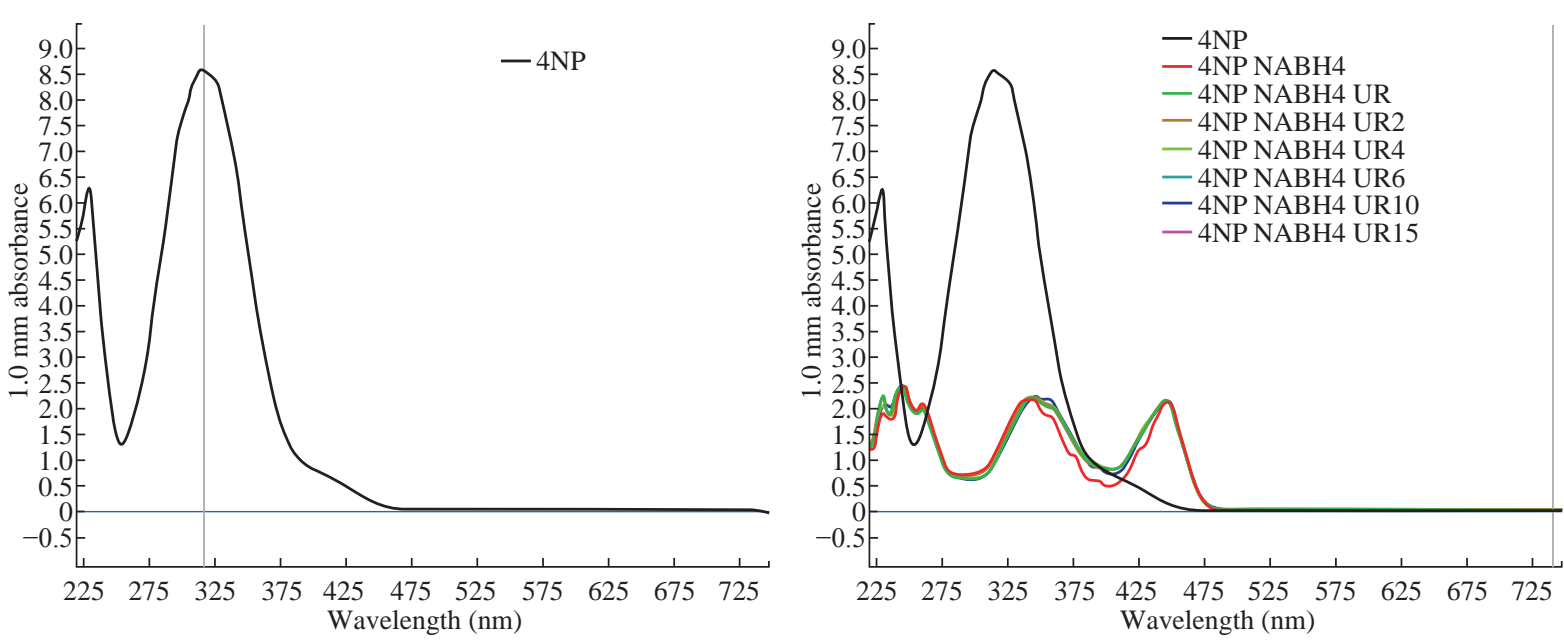

Fig. 10 Catalytic activity of unripe Tc-Ag NPs.

\section{Conclusions}

The biosynthesized Tc-Ag NPs by ripe and unripe fruit extracts were the first of their kind. Several scientists worked with various parts of Tinospora cordifolia, but so far no one has worked on its fruits which were reported to have high medicinal value. The bio-synthesized Tc-Ag NPs showed surface Plasmon resonance (SPR) band at 431 and $421 \mathrm{~nm}$ respectively. The functional groups of bioactive components were identified which reduced silver nitrate to silver ions. The size distribution of biosynthesized Tc-Ag NPs of ripe and unripe fruits was around $35 \pm 1$ and 35.8 $\pm 1 \mathrm{~nm}$, and the NPs exhibited high stability due to their negative zeta potential. Tc-Ag NPs revealed that they had good antimicrobial activity and they also had effective free radical scavenging efficacy, exhibiting potential catalytic activity by converting 4 nitro-phenol to 4 amino phenols at rapid pace. It was concluded that the Tc-Ag NPs synthesized by ripe and unripe fruits almost showed similar results, so both of them proved to have excellent multifunctional biomedical applications.

\section{Acknowledgements}

The authors were grateful to DST-PURSE Programme, sponsored by DST New Delhi, for providing fellowship to work under this program at Sri Venkateswara University, Tirupati.

\section{Authors' contributions}

Praveena Kanagala, Susmila Aparna Gaddam, and Venkata Subbaiah Kotakadi contributed equally to the work, with planning, design and execution by Venkata
Subbaiah Kotakadi

\section{Funding}

The authors declare that this research work did not receive any specific grants

\section{Data availability}

The research data associated with the manuscript have been provided within the manuscript

\section{Conflict of Interests}

The authors declare that no competing interest exists.

\section{References}

[1] M.A. Albrecht, C.W. Evans, and C.L. Raston, Green chemistry and the health implications of nanoparticles. Green. Chem., 2006, 8: 417-432.

[2] A.M .Smith, H. Duan, M.N. Rhyner, et al., A systematic examination of surface coatings on the optical and chemical properties of semiconductor quantum dots. Phys. Chem. Chem. Phys., 2006, 8: 3895-3903.

[3] P.K. Jain, X. Huang, I.H. El-Sayed, et al., Noble metals on the nanoscale: Optical and photothermal properties and some applications in imaging, sensing, biology, and medicine. Acc. Chem. Res., 2008, 41: 1578-1582.

[4] G.J. Kearns, E.W. Foster, J.E. Hutchison, Substrates for direct imaging of chemically functionalized $\mathrm{SiO} 2$ surfaces by transmission electron microscopy. J. Anal. Chem., 2006, 78: 298-303.

[5] L.S. Nair, C.T. Laurencin, Silver nanoparticles: Synthesis and therapeutic applications. J. Biomed. Nanotechnol. 2007, 3: 301-316.

[6] V.S. Kotakadi, Y. Subba Rao, S.A. Gaddam, et al., Simple and rapid biosynthesis of stable silver nanoparticles using dried leaves of Catharanthus roseus. Linn. G. Donn and its anti microbial activity. Colloids Surf. B: Biointerfaces. 2013, 105: 194-198.

[7] V.S. Kotakadi, S.A. Gaddam, Y. Subba Rao, et al., Biofabrication of silver nanoparticles by Andrographis 
paniculata. Eur. J. Med. Chem., 2014, 73: 135-140.

[8] S.A. Gaddam, V.S. Kotakadi, Y. Subba Rao, et al., Efficient and robust biofabrication of silver nanoparticles by Cassia alata leaf extract and their antimicrobial activity. J. Nanostruct. Chem., 2014, 4: 82-88.

[9] V.S. Kotakadi, S.A. Gaddam, S.K. Venkata, et al., New generation of bactericidal silver nanoparticles against different antibiotic resistant Escherichia coli strains. Appl. Nanosci., 2015, 5: 847-855.

[10] V.S. Kotakadi, S. A.Gaddam, S.K. Venkata, et al., Ficus fruit-mediated biosynthesis of silver nanoparticles and their antibacterial activity against antibiotic resistant E.coli strains. Curr. Nanosci. 2015, 1: 527-538.

[11] V.S. Kotakadi, S.A. Gaddam, S.K. Venkata, et al., Biofabrication and spectral characterization of silver nanoparticles and their cytotoxicstudies on human CD34 +ve stem cells. Biotech. 2016, 6: 216- 221

[12] K.V. Sucharitha, G.S. Aparna, K.V. Subbaiaih, et al., Multifunctional silver nanoparticles by fruit extract of Terminalia belarica and their therapeutic applications: A 3-in-1 System. Nano. Biomed. Eng., 2018, 10(3): 279294.

[13] V.R. Netala, B. Suman, D. Latha, et al., Biogenesis of silver nanoparticles using leaf extract of Indigofera hirsuta L. and their potential biomedical applications (3in-1 system). Artific. Cells Nanomedic. Biotechnol., 2018, 46(1): 1138-1148.

[14] N. Prabhu Das, H.S. Nandhini, N. Sudeep, et al., An in vitro cytotoxic and genotoxic properties of Allmanda Cathartica L. latex green NPs on human peripheral blood mononuclear cells. Nano Biomed. Eng., 2017, 9: 314-323.

[15] S. Palithya, K.V. Subbaiah, J. Pechalaneni, et al., Biofabrication of silver nanoparticles by leaf extract of Andrographis serpyllifolia and their antimicrobial and antioxidant activity. Int. J. Nano. Dimens., 2018, 9: 398407.

[16] M.B. Galib, M. Mayur, J. Chandrashekhar, et al., Therapeutic potentials of metals in ancient India: A review through Charaka Samhita. J. Ayurveda. Integr. Med., 2011, 2: 55-63.

[17] A.U. Wijenayake, C.L. Abayasekara, H.M.T.G.A. Pitawala, et al., Antimicrobial potential of two traditional herbometallic drugs against certain pathogenic microbial species. BMC. Complement. Altern. Med., 2016, 16: $365-$ 378.

[18] P. Singh, Y.J. Kim, C. Wang, et al., The development of a green approach for the biosynthesis of silver and gold nanoparticles by using Panax ginseng root extract, and their biological applications. Artif Cells Nanomed Biotechnol. 2016, 44: 1150-1157.

[19] D. Ashok Kumar, V. Palanichamya Selvaraj Mohana Roopanb, Green synthesis of silver nanoparticles using Alternanthera dentata leaf extract at room temperature and their antimicrobial activity. Spectrochimica Acta Part A: Molecular and Biomolecular Spectroscopy, 2014, 127(5): 168-171.

[20] G.J. Edgar, R.D. Stuart-Smith, T.J. Willis, et al., Global conservation outcomes depend on marine protected areas with five key features. Nature, 2014, 506: 216-220.

[21] S. Kirti, N.P. Mishra, J. Singh, et al., Tinospora cordifolia (Guduchi), a reservoir plant for therapeutic applications: A Review. Indian J. Tradit Knowl. 2004, 3: 257-270.

[22] B. Misra, Bhava Prakash Nighantu, vol. 1, (Hindi commentary by K.C. Chunekar). Chowkhamba Vidya Bhavan, Varanasi, 1969: 269.

[23] K.R. Kirtikar, B.D. Basu, Indian Medicinal Plants, vol. 2. Lalit Mohan Basu, Leader Road, Allahabad, 1933: 77.

[24] P.V. Sharma, Dravya Guna Vigyan, vol. 2. Chowkhambha Vidya Bhavan, Varanasi, 1969: 680.

[25] S. Bapalalji, Nighantu Adarsh, vol. 1, (Hindi translation).
Chowkhambha Vidya Bhavan, Varanasi, 1969: 35.

[26] K.I. Maryamma, P.K. Ismail, C.B. Manmohan, et al., Ameliorating effect of Amrutha (Tinospoara cordifolia) in aflatoxicosis of ducks. J. Vet. Anim. Sci., 1990, 21: 93-96.

[27] M.K. Sangeetha, H.R. Raghavendran Balaji, V. Gayathri, et al., Tinospora cordifolia attenuates oxidative stress and distorted carbohydrate metabolism in experimentally induced type 2 diabetes in rats. J. Nat. Med., 2011, 65: 544-550.

[28] R. Gupta, V. Sharma. Ameliorative effects of Tinospora cordifolia root extract on histopathological and biochemical changes induced by aflatoxin-b(1) in mice kidney. Toxicol. Int., 2011, 18: 94-98.

[29] V. Sharma, D. Pandey, Protective Role of Tinospora cordifolia against lead-induced hepatotoxicity. Toxicol Int., 2010, 17: 12-17

[30] P. More, K. Pai. In vitro NADH-oxidase, NADPHoxidase and myeloperoxidase activity of macrophages after Tinospora cordifolia (guduchi) treatment. Immunopharmacol. Immunotoxicol., 2012, 34: 368-372.

[31] R. Upadhyaya, P.R. Pandey, V. Sharma, et al., Assessment of the multifaceted immunomodulatory potential of the aqueous extract of Tinospora cordifolia. Res. J. Chem. Sci. 2011, 1: 71-79.

[32] R. Raghu, D. Sharma, R. Ramakrishnan, et al., Molecular events in the activation of $\mathrm{B}$ cells and macrophages by a non-microbial TLR4 agonist, G1-4A from Tinospora cordifolia. Immunol. Lett., 2009, 123: 60-71.

[33] A.K. Mittal, A. Kaler, and U.C. Banerjee, Free radical scavenging and antioxidant activity of silver nanoparticles synthesized from flower extract of Rhododendron dauricum. Nano Biomed. Eng., 2006, 4: 118-124.

[34] J.J. Mock, M. Barbic, D.R. Smith, et al., Shape effects in Plasmon resonance of individual colloidal silver nanoparticles. J. Chem. Phys., 2002, 116: 6755- 6759.

[35] S. Vanaraj, B. Bhargavi Keerthana, and K. Preethi, Biosynthesis, characterization of silver nanoparticles using quercetin from Clitoria ternatea $\mathrm{L}$ to enhance toxicity against bacterial Biofilm. J. Inorg. Organomet. Polym., 2017, 27: 1412-1422.

[36] Y. Gavamukulya, E.N. Maina, A.M. Meroka, et al., Green Synthesis and characterization of highly stable silver nanoparticles from ethanolic extracts of fruits of Annona muricata. J. Inorg. Organomet. Polym., 2019, 30: 12311242.

[37] K.M. Ezealisiji, X.S. Noundou, and S.E. Ukwueze, Green synthesis and characterization of monodispersed silver nanoparticles using root bark aqueous extract of Annona muricata Linn and their antimicrobial activity. Appl Nanosci., 2017, 7: 905-911.

[38] M. Danaei, M. Dehghankhold, S. Ataei, et al., Impact of particle size and polydispersity index on the clinical applications of lipidic nanocarrier systems. Pharmaceutics. 2018, 10: 1-17.

[39] K. Jyoti, M. Baunthiyal, and A. Singh, Characterization of silver nanoparticles synthesized using Urtica dioica Linn. leaves and their synergistic effects with antibiotics. Journal of Radiation Research and Applied Sciences, 2016, 9: 217-227.

[40] S. Kaviya, J. Santhanalakshmi, B. Viswanathan, et al., Biosynthesis of silver nanoparticles using citrus sinensis peel extract and its antibacterial activity. Spectrochimica Acta Part A: Molecular and Biomolecular Spectroscopy, 2011, 79: 594-598.

[41] G. Magudapatty, P. Gangopaghyayrans, B.K. Panigrahi, et al., Electrical transport studies of Ag nanoclusters embedded in glass matrix Phys B, 2001, 299: 142-146.

[42] O. Blokhina, E. Virolainen, and K.V. Fagerstedt, Antioxidants, oxidative damage and oxygen deprivation stress: A review. Ann. Bot., 2003, 91(2): 179-194. 
[43] A. Scalbert, I.T. Johnson, and M. Saltmarsh, Polyphenols: Antioxidants and beyond. Am J Clin Nutr., 2005, 81(1): 215S-217S.

[44] M. Bhagat, R. Anand, R. Datt, et al., Green synthesis of silver nanoparticles using aqueous extract of Rosa brunonii Lind and their morphological, biological and photocatalytic characterizations. J. Inorg. Organomet. Polym., 2019, 29(3): 1039-1047.

[45] J. Park, S.H. Cha, S. Cho, et al., Green synthesis of gold and silver nanoparticles using gallicacid: catalytic activity and conversion yield toward the 4-nitrophenol reduction reaction. J. Nanopart. Res., 2016, 18: 166-179.

[46] A. Gangula, R. Podila, M. Ramakrishna, et al., Catalytic reduction of 4-nitrophenol using biogenic gold and silver nanoparticles derived from Breynia rhamnoides. Langmuir, 2011, 27(24): 15268-15274.

Copyright $@$ Praveena Kanagala, Susmila Aparna Gaddam, Priyanka Gunji, Venkata Subbaiah Kotakadi, Chandra Mouli Kalla, Vijaya Tartte, and Divi Venkata Ramana Sai Gopal. This is an open-access article distributed under the terms of the Creative Commons Attribution License, which permits unrestricted use, distribution, and reproduction in any medium, provided the original author and source are credited. 